\title{
Ética e pesquisa biomédica em sociedades indígenas no Brasil
}

\author{
Ethics and biomedical research in Amerindian \\ societies in Brazil
}

Carlos E. A. Coimbra Jr. 1

Ricardo Ventura Santos 1,2

\footnotetext{
1 Escola Nacional de Saúde Pública, Fundação Oswaldo Cruz, Rua Leopoldo Bulhões 1480, Rio de Janeiro, RJ 21041-210, Brasil.

2 Departamento de Antropologia,

Museu Nacional,

Quinta da Boa Vista s/no,

Rio de Janeiro, RJ

20940-040, Brasil.
}

Abstract This paper discusses the ethics of biomedical research in Amerindian populations of Brazil, focusing on the obtainment of informed consent in field work involving the collection of biological samples. The authors emphasize that the current legislation does not specifically regulate biomedical research in these populations. From an anthropological standpoint, the authors discuss some of the difficulties in obtaining a "truly" informed consent. The rel evance of the discussion on research ethics is of growing importance due to the possibility of commercial use of human bi ological samples, as illustrated by the ongoing debate on the granting of patents to human genetic materials.

Key words Ethics; Research; Biomedicine; Genetics; Amerindians

Resumo Estetrabalho discute questões relativas à ética da investigação biomédica em populações indígenas brasil leiras, em particular no que tange à obtenção de consentimento pós-informacional em pesqui sas que envol vam a coleta de amostras biológi cas. Enfatiza-se que nada há de específico na legi slação atual com respei to à pesquisa biomédica nestas populações. A partir de uma perspectiva antropológica, os autores analisam algumas das dificuldades para a obtenção do consenti mento "realmente" informado. Chama-se atenção para a importância das discussões sobre ética em pesquisa face a possibilidade de utilização comercial de amostras biológi cas, como exemplificado pelo atual debate sobre patenteamento de material genético humano.

Palavras-chave Ética; Pesquisa; Biomedicina; Genética; Índios 


\section{Introdução}

Questões de ordem ética envolvendo pesquisa biomédica em seres humanos têm recebido cada vez mais atenção no Brasil. Em parte resultante de uma nova postura da própria comunidade científica, mas também decorrente de pressões exercidas por agências financiadoras, comitês de ética vêm se organizando em institutos de pesquisa e universidades. O lançamento da revista Bioética, publicada pelo Conselho Federal de Medicina a partir de 1993, assim como o número crescente de publicações que lidam com temas ligados à ética da prática médica propriamente dita e da aplicação de tecnologias em saúde, refletem o grau de preocupação e interesse dos profissionais das mais distintas áreas pelo tema (Garcia \& Chamas, 1996; Garrafa, 1995; Neves, 1996; Schramm, 1995).

Nosso objetivo neste texto é refletir sobre certas questões relativas à ética da pesquisa biomédica em populações indígenas no Brasil, em particular no que se refere ao trabalho de campo envolvendo a coleta de amostras biológicas. Como é sabido, estes grupos não comungam dos mesmos valores e sistema de crenças e práticas médicas das ditas sociedades de cultura ocidental. Apesar disso, nada há de específico na legislação, quer seja nacional ou internacional, com respeito à ética da prática médica e/ ou da pesquisa biomédica entre estas populações. Este é um debate importante, particularmente por estar em processo de revisão a resolução do Conselho Nacional de Saúde que normatiza a pesquisa biomédica em seres humanos no Brasil.

Ética, Pesquisa Biomédica e Sociedades Indígenas

No plano internacional, não há um corpo de regras específicas e de ampla aceitação pelos diversos países que regule questões ligadas à ética da pesquisa em biomedicina. Os princípios básicos pelos quais se pautam comitês de ética e investigadores derivam do Código de Nuremberg (1947), da Declaração de Helsinki (1964 e emendada em 1975) e das Diretrizes Éticas Internacionais para Pesquisas Biomédicas Envolvendo Seres Humanos, proposta pelo Conselho para Organizações Internacionais de Ciências Médicas e Organização Mundial da Saúde em 1993 (Anônimo, 1995).

No Brasil, a pesquisa em saúde é normatizada através da Resolução 01/ 88 do Consel ho Nacional de Saúde (CNS, 1995). Esta resolução reza que pesquisa envolvendo seres humanos deve "contar com o consentimento [pós-informacional ] do indivíduo objeto da pesquisa ou seu representantelegal" (Cap. II, Art. 5o). Consentimento pós-informacional é definido como "... o acordo por escrito mediante o qual o indivídu o objeto da pesquisa ou...seu representante legal, autoriza sua partici pação na pesquisa, com pleno conhecimento da natureza dos procedimentos e riscos a que se submeterá, com a capaci dade de livre arbítrio e sem qualquer coação" (Cap. II, Art. 10o). O consentimento deve ser assinado pelo próprio indivíduo ou seu representante legal. No caso de não alfabetizados, a Resolução prevê que o indivíduo deverá imprimir sua impressão digital.

Não há qualquer capítulo ou artigo na Resolução 01/88 que se refira especificamente à pesquisa em populações indígenas. $\mathrm{O}$ que se poderia considerar como mais próximo é o Capítulo IV, que trata da pesquisa em situações onde não haja "condições de compreensão", por se tratar de menores de idade ou no caso de indivíduos que, por razões várias, não se encontrem em condições de dar "conscientemente" seu consentimento. Nestes casos, o pesquisador deverá obter "consentimento escrito de participação aprovado pelo Comitê de Ética da instituição...eassinado pel o responsável legal".

Se por um lado a Resolução do CNS é omissa em relação às populações indígenas, por outro a legislação indigenista é omissa em relação às pesquisas biomédicas. Somente a portaria no 745 de 1988 da Fundação Nacional do Índio (Funai), que normatiza a concessão de autorização para o ingresso em área indígena, dispõe sobre a realização de pesquisa científica (Guimarães, 1989). Neste caso, reza apenas que o pedido para realização de pesquisa "...só será analisado pela Funai à vista de parecer favorável do Consel ho Nacional de Desenvolvimento Científico e Tecnológico" (CNPq), nada indicando sobre a pesquisa biomédica em si e/ ou seus desdobramentos para as comunidades. No âmbito do CNPq, a responsabilidade pela análise dos projetos encaminhados pela Funai é da área das ciências sociais. Não envolve, portanto, as áreas de saúde ou de ciências biológicas.

A Portaria Interministerial no 278 de 18/11/1988, promulgada pelos Ministérios da Ciência e Tecnologia e do Interior, é também omissa em relação à pesquisa biomédica e em saúde. Seu Artigo 1o explicita a necessidade de autorização somente para pesquisa antropológica ou lingüística (Guimarães, 1985:108). 
As Sociedades Indígenas e 0

Consentimento Pós-Informacional

Como indica a resolução do CNS, um elemento central a ser considerado na pesquisa diz respeito à obtenção do consentimento pós-informacional. A seguir problematizamos esta questão no que tange às sociedades indígenas, chamando atenção para algumas dificuldades de ordem ética e operacional envolvidas na obtenção de um consentimento "realmente" informado.

Estima-se em aproximadamente 220.000 a população indígena no país, com cerca de $60 \%$ deste contigente vivendo na Amazônia. Um aspecto a ser destacado é a grande diversidade sócio-cultural. São mais de 170 etnias, com sistemas sociais e políticos próprios, vivendo em aldeamentos, postos indígenas, missões religiosas e até mesmo na periferia de cidades. Do ponto de vista lingüístico, o panorama é igualmente complexo, com um número superior a 150 línguas. Deve-se ainda chamar atenção para a heterogeneidade quanto à história e situação de contato destes grupos com a sociedade nacional. Enquanto al guns ainda mantêm-se relativamente mais isolados, outros participam com diferentes graus de envolvimento na economia de mercado. Tamanha diversidade implica que a categoria "sociedade indígena" é algo complexo e multifacetado, englobando populações com características sócio-culturais e trajetórias históricas diversas. Isto constitui, por si, grande desafio à aplicação de procedimentos normatizados a partir de um conjunto de princípios éticos e jurídicos fundamentados em um "ethos" ocidental.

A obtenção do consentimento pós-informacional baseia-se no princípio segundo o qual o indivíduo, após ter sido informado acerca dos objetivos e procedimentos da investigação, decidirá, individualmente, anuir ou não à pesquisa. Desnecessário dizer que os códigos de ética são estruturados a partir de uma concepção de indivíduo construída a partir de uma ótica ocidental. Nesta acepção, exalta-se uma vertente interna de indivíduo segundo a qual o princípio de livre arbítrio e de escolha individual são centrais. Aqui reside importante contraste com as sociedades indígenas, nas quais, comumente, prioriza-se uma construção coletiva de indivíduo (Seeger et al., 1979). Estritamente falando, a obtenção do consentimento pós-informacional individual é revestida por certa dose de etnocentrismo, já que significa aplicar categorias geradas e valorizadas em um determinado contexto sócio-cultural a outros que não necessariamente comparti-
Iham dos mesmos valores. Entre os Xavánte, por exemplo, dificilmente um membro da comunidade decidirá, individualmente, quanto a sua participação em um projeto de pesquisa sem que, antes, a questão seja discutida no warã, importantíssima instância decisória da sociedade Xavánte constituída pelos homens mais velhos. Este exemplo é ilustrativo, pois sugere que a instância coletiva de decisão pode ser mais importante que a individual.

Como obter uma certificação de que o indivíduo concorda em participar da pesquisa? Mais uma vez, não há como fugir de especificidades culturais e as opções disponíveis usualmente limitam-se a assinatura ou impressão digital, e destas em particular, já que a maioria dos indígenas não são alfabetizados. Muito cedo no processo de socialização na sociedade ocidental aprende-se que $o$ ato de impregnar a ponta dos dedos com tinta e imprimir uma certa característica morfológica em papel está relacionado a associar sua pessoa (sua individualidade) a uma idéia, a um documento. Se o ato de marcar um papel com a impressão digital é mecanicamente simples, sociologicamente articula-se com uma complexa rede de elementos jurídicos e filosóficos. Uma impressão digital só é um real atestado de aprovação se, para o indivíduo, estiver clara a vinculação entre o biológico (i.e., o dermatóglifo) e o social e jurídico (i.e., o valor da impressão como identidade).

A resolução do CNS também prevê a possibilidade do pesquisador obter o consentimento para a realização da investigação não diretamente do indivíduo em apreço, mas de seu "responsável". Neste caso, remete-se a questão ao papel exercido pelo órgão tutor - a Funai que, como representante legal dos indígenas, poderia dar o consentimento para a pesquisa. No entanto, o órgão não conta com um comitê de bioética para avaliar os projetos que lhes são enviadose, além disso, depende de parecer do CN Pq para autorizar o projeto de pesquisa que, como já vimos, é analisado pela área de ciências sociais daquele Conselho.

Outro ponto importante diz respeito às representações indígenas acerca do processo terapêutico, o que pode fazê-los mais "suscetíveis", culturalmente falando, a se submeterem à coleta de amostras de sangue ou biópsias. Como bem documentado na literatura em etnomedicina das sociedades indígenas, é comum a representação que privilegia a inoculação como via para a administração de remédios. Daí porque seringas e injeções, que comumente encontram grande objeção em nossa sociedade, são em geral bem recebidas pelos indígenas, já que são percebidas como a via 
mais direta para se atingir o foco da doença situado no interior do corpo ou no próprio sangue. Entre os Warí (Pacaánova), por exemplo, Conklin (1994) relata a preferência por medicamentos injetáveis por serem estes considerados mais fortes e eficazes. Procedimentos terapêuticos envolvendo a eliminação de sangue, seja através de escarificações ou incisões diretas sobre pequenos vasos, também são comumente descritos na literatura etnográfica. Deste modo, em certos contextos culturais, procedimentos "propedêuticos" da medicina ocidental podem ser interpretados como atos "terapêuticos". Esta é uma das razões pelas quais raramente os pesquisadores relatam maiores dificuldades na obtenção de amostras de sangue. Se, por um lado, a representação indígena facilita o trabal ho de coleta das amostras, por outro impõe uma dificuldade adicional para o pesquisador: deixar claro quais são os "reais" intuitos que norteiam o trabal ho. A obtenção do consentimento pós-informacional que faça uso unicamente de conceitos indígenas de enfermidade e cura não é ética, pois sugere uma intervenção médico-terapêutica quando, na realidade, trata-se da coleta de amostras biológicas que, posteriormente, poderão vir a ser processadas para os mais variados fins.

Não é incomum na rotina da pesquisa biomédica em áreas indígenas a "permuta" de amostras de material por assistência médica e insumos (vacinas e/ ou medicamentos). Será esta uma base de "troca" válida? Em nossa opinião, os termos do "acordo" devem almejar a compreensão do indígena acerca da perspectiva (ocidental) que norteia a investigação e que, a longo prazo, determinará o que se poderá fazer com o material.

As considerações acima sugerem que, paradoxalmente, quanto mais isolada ou distanciada for uma sociedade do modelo ocidental, talvez mais fácil seja obter certificações de consentimento. Aqui, contudo, há de se diferenciar entre a dimensão "mecânica" que reveste o ato de consentir (representada, por exemplo, pela aposição de impressões digitais sobre um documento) e esferas cognitivas mais profundas, nas quais a mecânica do processo articula-se com a compreensão de seus significados e implicações no plano ocidental.

\section{Do imaginário ao concreto}

A esta altura o leitor deve estar se perguntando se não estamos no campo de filigranas antropológicas, incompatíveis com as demandas do mundo "real", no qual as pesquisas precisam ser realizadas e o fator tempo não permite que os investigadores passem, digamos, semanas ou meses em uma aldeia para só então começar a compreender as categorias nativas e, aí, obterem o consentimento de uma forma culturalmente mais adequada. Em parte, o leitor tem razão: o ponto a ser atingido é o de um equilíbrio entre transparência e respeito para com o "outro" e operacionalidade.

Exemplos concretos ajudam-nos a materializar teorizações. Por meio de uma rápida incursão no campo da genética veremos que os pontos levantados acima nem sempre são apenas filigranas. São questões concretas que precisam (e precisarão) ser enfrentadas cada vez mais freqüentemente, tanto pelos pesquisadores como pela sociedade em geral.

As populações indígenas amazônicas estão entre as mais bem geneticamente estudadas no mundo. A coleta de amostras de sangue tem sido fundamental a estas pesquisas, que até recentemente baseavam-se primordialmente na análise das freqüências de vários marcadores sangüíneos para caracterizar o perfil genético das populações. Destas pesquisas não se esperavam produtos comercializáveis. Os resultados eram eminentemente acadêmicos, principalmente artigos em revistas especializadas, livros e/ ou dissertações.

Avanços técnicos alcançados nos últimos anos permitiram aos geneticistas mudar o enfoque de suas análises, que agora residem cada vez mais no estudo do próprio material genético (DNA). Esta transformação metodológica veio acompanhada por um importante desdobramento: as análises genéticas contemporâneas permitem identificar e delimitar genes e estes, na legislação de certos países, podem vir a ser patenteados. Ou seja, se até num passado recente o valor intrínseco de uma amostra de sangue residia em seu potencial de adicionar ao conhecimento científico no sentido lato, no presente pode levar também a lucros da ordem de milhões de dólares no caso da "descoberta" de um gene patenteável. Por exemplo, Dickson (1996) menciona que, no ano passado, foi vendido nos E.U.A. o direito de exploração comercial de um gene relacionado com a obesidade por 70 milhões de dólares. Obviamente, a identificação de um gene de valor comercial é menos regra que exceção.

Ainda que as possibilidades de identificação e patenteamento de genes não se restrinjam às populações indígenas, elas são de especial interesse para o que alguns já denominam "prospecção de genes" (Jayaraman, 1996). Isto porque tendem a ser geograficamente bem delimitadas e seus membros compartilharem de uma história biológica em comum. Ainda mais 
importante, geralmente descendem de um pequeno número de fundadores, sendo portanto geneticamente mais homogêneas. Por exemplo, numa comunidade Xavánte com a qual temos trabal hado quase metade dos 500 indivíduos são descendentes diretos ou indiretos de um único homem falecido na década de 70.

É importante deixar claro que a discussão acerca do patenteamento de produtos biológicos oriundos de pesquisas realizadas em populações indígenas não é novidade. Haja vista, por exemplo, as polêmicas que envolvem a identificação e comercialização de substâncias ativas com potencial farmacológico, assim como de variedades locais de plantas cultiváveis resistentes a pragas ou com características fenotípicas de interesse econômico, identificadas a partir de pesquisas etnobotânicas (Boom, 1990; Gray, 1995; Kloppenburg, 1988; Posey, 1990). A questão do patenteamento e comercialização de genes humanos obtidos a partir de indígenas é ainda mais delicada. Isto porque, neste caso, o produto patenteado pode vir a ser diretamente traçado ao corpo de um indivíduo.

O cenário de identificação e patenteamento de genes humanos, que há alguns anos era quase que sinônimo de ficção, aproxima-se mais e mais da realidade. Um recente artigo publicado na revista Nature chama atenção para a possibilidade da seguinte situação se materializar: "um grupo de indivíduos - [por exemplo] índios da América do Sul participando de um projeto em antropologia...concorda em prover amostras de sangue para um grupo de pesquisa. Na ocasião, os termos do 'contrato' são relati vamente informais. Os índios aceitam algum material biomédico e ajuda na construção da uma escol a local... Três anos depois, os direitos para exploração de material genético identificado a partir das amostras são vendidos pel os pesquisadores para uma grande companhia farmacêutica por, digamos, 20 mil hões de dólares" (Dickson, 1996:11).

Nosso intuito não foi esgotar a discussão sobre as questões de ordem ética envolvidas na pesquisa biomédica em populações indígenas. Inclusive nos detivemos mais em apenas uma das facetas da questão, qual seja, o dilema ético envolvido na coleta de amostras biológicas. Outras questões não menos importantes dizem respeito ao retorno para o indivíduo e/ ou comunidades no caso de lucros decorrentes da exploração comercial do material coletado. Os pesquisadores da área biomédica geralmente estão tão envolvidos com as complexidades técnicas e teóricas das várias etapas de coleta e análise das amostras, que pouca atenção conferem as não menos complexas questões de ordem sócio-cultural e políticas inerentes à pesquisa.

Contudo, os novos rumos da pesquisa biomédica em seres humanos, especial mente no que se refere às populações indígenas, requerem que, cada vez mais, não somente os sujeitos diretamente envolvidos, como também os organismos competentes e a sociedade em geral, estejam muito cientes acerca dos possíveis desdobramentos destas investigações. 


\section{Referências}

ANÔNIMO, 1995. Diretrizes éticas internacionais para pesquisas biomédicas envolvendo seres humanos. Bioética, 3:95-136.

BOOM, B. M., 1990. Ethics in ethnopharmacology. In: Ethnobiology: Implications and Applications (D. A. Posey \& W. L. Overal, orgs.), vol. 2, pp. 147-153. Belém: Museu Paraense Emílio Goeldi.

CNS (Conselho Nacional de Saúde, Brasil), 1995. Resolução No. 01/88: normas de pesquisa em Saúde. Bioética, 3:137-154.

CONKLIN, B. A., 1994. O sistema médico Warí (Pakaanóva). In: Saúdee Povos Indígenas (R.V. Santos \& C.E.A. Coimbra J r., orgs. ), pp. 161-186. Rio de Janeiro: Editora Fiocruz.

DICKSON, D., 1996. Whose genes are they anyway? Nature, 381:11-14.

GARCIA, E. S. \& CHAMAS, C. I., 1996. Genética molecular: Avanços e problemas. Cadernos de Saúde Pública, 12:103-107.

GARRAFA, V., 1995. A Dimensão da Ética em Saúde Pública. São Paulo: Faculdade de Saúde Pública, Universidade de São Paulo.

GRAY, A., 1995. O impacto da conservação da biodiversidade sobre os povos indígenas. In: A Temática Indígena na Escola (A.L. da Silva \& L.D.B. Gru- pioni, orgs.), pp. 107-124. Brasília: Ministério da Educação e do Desporto/São Paulo: Grupo de Educação Indígena, Universidade de São Paulo.

GUIMARÃES, P. M., 1989. Legislação Indigenista Brasileira. São Paulo: Edições Loyola.

JAYARAM AN, K.S., 1996. Gene-hunters home in on India. Nature, 381(May 2):13

KLOPPENBURG, J., 1988. First the Seed: The Political Economy of Plant Biotechnology, 1492-2000. Cambridge: Cambridge University Press.

NEVES, M. C. P., 1996. A fundamentação antropológica da bioética. Bioética, 4:7-16.

POSEY, D. A., 1990. The application of ethnobiology in the conservation of dwindling natural resources: Lost knowledge or options for the survival of the planet. In: Ethnobiology: Implications and Applications (D. A. Posey \& W. L. Overal, orgs.), vol. 1, pp. 47-60. Belém: Museu Paraense Emílio Goeldi.

SEEGER, A.; DA M ATTA, R. \& VIVEIROS DE CASTRO, E., 1979. A construção da pessoa nas sociedades indígenas brasileiras. Boletim do Museu Nacional (Antropologia), 32:1-37.

SCHRAMM, F.R., 1995. A terceira margem da saúde: A ética "natural". Manguinhos, 1:54-68. 